References

1 McNicol K N, et al. Spectrum of asthma in children. I. Clinical and physiological components; II. Allergic components; III. Psychological and social components. Br Med J 1973; iv: 7-11; 12-6; 16-20.

2 Murray A B, Fraser B M, Hardwick D F, Pirie G E. Letter: Chronic asthma and growth failure in children. Lancet 1976; ii: 197-8.

3 Kerrebijn K F, De Kroon J P M. Effect on height of corticosteroid therapy in asthmatic children. Arch Dis Child 1968; 43: 556-61.

4 McNichol K N, Williams H E, Gillam G L. Chest deformity, residual airways obstruction and hyperinflation, and growth in children with asthma. Arch Dis Child 1970; 45: 783-8.

5 Tanner J M, Whitehouse R H, Takaishi M. Standards from birth to maturity for height, weight, height velocity, and weight velocity; British children 1965. Arch Dis Child 1966; 41: 613-35.
6 Tanner J M, Whitehouse R H, Hughes P C R, Vince F P. Effects of human growth treatment for 1 to 7 years on growth of 100 children, with growth hormone deficiency, low birthweight, inherited smallness, Turner's syndrome, and other complaints. Arch Dis Child 1971 ; 46: 745-82.

7 McCance $\mathrm{R}$ A, Widdowson $\mathrm{E}$ M. The composition of foods. Medical Research Council Special Report Series No 297. London: HMSO, 1960.

8 Department of Health and Social Security. Recommended intakes of nutrients for the United Kingdom. Reports on Public Health and Medical Subjects No 120. London: HMSO, 1979.

Correspondence to $\mathrm{Dr}$ J J Cogswell, Department of Paediatrics, Poole General Hospital, Longfleet Road, Poole, Dorset BH15 2JB.

Received 23 November 1981

\title{
Effect of a rocking bed on apnoea of prematurity
}

\author{
S J TUCK, P MONIN, C DUVIVIER, T MAY, AND P VERT \\ Service de Médecine Néonatale, Maternité Universitaire, Nancy, France
}

SUMMARY We describe a rocking bed for use in incubators. Its effect was studied in 12 preterm infants with idiopathic apnoea, using each as his own control. All but one had less apnoea when the bed was rocking than when it was still. Apnoea associated with a significant fall in transcutaneous $\mathrm{Po}_{2}$ was less frequent, and fewer interventions were needed to terminate apnoeic attacks.

Various forms of repeated sensory stimulationsuch as tactile stimulation or the use of irregularly oscillating waterbeds - can reduce apnoea in preterm infants. This approach to the management of recurrent apnoea avoids the potential hazards of treatment with continuous positive airways pressure (CPAP) or methylxanthines.

We have constructed a bed which imparts a regular cephalo-caudal rocking movement, not exceeding $3^{\circ}$ in either direction, in the hope of preventing apnoeic attacks by vestibular stimulation.

\section{The apparatus}

The rocking bed consists of a rectangular aluminium tray, mounted on pivots near the midpoints of its 2 longer sides. The regular rocking movement is obtained by alternate inflation and passive deflation of a small bellows beneath one end of the tray. The bellows is connected by a tube to a control unit beside the incubator. This contains a reservoir of compressed air, maintained by an electric pump, and a valve through which the bellows are automatically connected in turn to the reservoir, for inflation, and to the atmosphere, for deflation. Variable resistances are included in both parts of the circuit, so that inflation time and deflation time, as well as the cycle rate, can be altered separately.

\section{Patients}

We studied 12 infants with recurrent apnoea for which no neurological, metabolic, or infective cause could be found. All had had at least 3 episodes of apnoea ( $>12$ seconds) with bradycardia $(<100 /$ minute) in the preceding 24 hours, or 2 in the preceding 6 hours. Gestation ranged from 26 to 32 (mean 29.5) weeks, birthweight from 800 to 1700 (mean 1210) g, and postnatal age from 2 to 45 (mean 14) days. In no case did the sum of gestational and postnatal age exceed 34 weeks.

Four infants were receiving added oxygen $\left(\mathrm{F}_{1} \mathrm{O}_{2}<0 \cdot 34\right)$. Only one had received theophylline, 5 days previously.

\section{Methods}

Each infant was studied for two consecutive equal periods. The bed was rocking during one, and was still during the other, the sequence being randomly 
determined. Transcutaneous $\mathrm{Po}_{2}\left(\mathrm{TcPo}_{2}\right)$ (Helliger transoxode), heart rate, and impedance pneumogram (Hewlett Packard-monitor) were recorded throughout (Bryans B5316 multichannel recorder). For the 10 enterally-fed babies, recording began at the time of gavage: both study periods lasted 6 hours for 8 infants fed 3-hourly, and 8 hours for 2 infants fed 4-hourly. The other 2 babies were each studied for two consecutive 4-hour periods.

The infants' position was not changed from prone to supine, or vice-versa, but otherwise they were nursed as usual. Inspired oxygen concentration $\left(\mathrm{F}_{1} \mathrm{O}_{2}\right)$ and rectal temperature were recorded hourly and kept as constant as possible. One of us (SJT or TM) remained beside the infant to ensure satisfactory recordings, and to document any active intervention to terminate apnoeic attacks, but we tried to avoid influencing nursing care.

For analysis, apnoea was defined as cessation of respiratory movements $>12$ seconds. This arbitrary period was chosen for ease of measurement at the paper speed used. $\mathrm{TcPo}_{2}$ recordings were not perfectly continuous, because of elective repositioning, and occasional accidental detachment, of the electrode. If apnoea occurred when $\mathrm{TcPo}_{2}$ recording was unsatisfactory, all $\mathrm{TcPo}_{2}$ data for that infant were discarded. Statistical significance was assessed using Wilcoxon's signed rank sum test for paired samples.

\section{Results (Table)}

In 6 cases the control period preceded rocking; in 6 rocking preceded control. Results were similar for the two groups. The rate of rocking, constant for each individual, ranged from 10 to 22 (mean $16 \cdot 5$ ) cycles/minute, but showed no correlation with results observed. There were no significant differences in rectal temperature or $\mathrm{F}_{1} \mathrm{O}_{2}$ during rocking and control periods.

The total number of apnoeic episodes varied considerably between individuals; $<10$ for six infants, between 10 and 20 for four, and between 21 and 62 for two. One baby had a single, severe, apnoeic attack, which occurred when the bed was rocking. Otherwise all had less apnoea when the bed was rocking than when it was still. Apnoea with bradycardia, and bradycardia without cessation of respiratory movements, were also significantly reduced during rocking.

$\mathrm{TcPO}_{2}$ recordings were satisfactory for 9 infants. During rocking, there were fewer apnoeic attacks in which $\mathrm{TcPO}_{2}$ fell by more than $10 \mathrm{mmHg}$, and fewer in which $\mathrm{TcPo}_{2}$ fell below an arbitrary absolute level of $50 \mathrm{mmHg}$.

Six infants had apnoeas terminated by extra stimulation; for all but one such interventions were fewer during rocking. Overall there were 28 interventions when the bed was still, compared with 6 during rocking.

\section{Discussion}

Recurrent apnoea in preterm infants is associated with considerable mortality and risk of handicap. CPAP and methylxanthines (aminophylline, theophylline, caffeine) are effective in reducing apnoea, ${ }^{\mathbf{1}}$ but have not yet clearly been shown to improve long-term outcome. Furthermore, concern about their potential side effects ${ }^{3}{ }^{4}$ may lead to reluctance to institute treatment, especially in 'mild' cases(R A K Jones, 1981, personal communication).

Less aggressive management, based on sensory stimulation, presents certain practical difficulties. Tactile stimulation ${ }^{5}$ has a useful effect, but is costly in nursing time. Vestibuloproprioceptive stimulation

Table Effect of rocking on the incidence of apnoea and bradycardia

\begin{tabular}{|c|c|c|c|c|c|c|c|}
\hline \multirow[t]{3}{*}{ Event } & \multirow{2}{*}{\multicolumn{2}{|c|}{$\begin{array}{l}\text { Total no of } \\
\text { events recorded }\end{array}$}} & \multicolumn{4}{|c|}{ No of infants for whom event } & \multirow{3}{*}{$\begin{array}{l}\text { Statistical significance } \\
\text { of change in } \\
\text { number of events* } \\
P\end{array}$} \\
\hline & & & \multirow{2}{*}{$\begin{array}{l}\text { Was } \\
\text { recorded }\end{array}$} & \multirow{2}{*}{$\begin{array}{l}\text { Was } \\
\text { unchanged } \\
\text { (frequency } \\
\text { not zero) }\end{array}$} & \multicolumn{2}{|c|}{ Was more frequent } & \\
\hline & Rocking & Control & & & $\begin{array}{l}\text { In } \\
\text { rocking period }\end{array}$ & $\begin{array}{l}\text { In } \\
\text { control period }\end{array}$ & \\
\hline $\begin{array}{l}\text { Apnoea ( }>12 \text { seconds) } \\
\text { Apnoea with bradycardia } \\
(<100 / \mathrm{min})\end{array}$ & $\begin{array}{l}69 \\
58\end{array}$ & $\begin{array}{l}119 \\
101\end{array}$ & $\begin{array}{l}12 \\
12\end{array}$ & $\begin{array}{l}0 \\
2\end{array}$ & $\begin{array}{l}1 \\
1\end{array}$ & $\begin{array}{r}11 \\
9\end{array}$ & $\begin{array}{l}<0.001 \\
<0.01\end{array}$ \\
\hline \multirow{4}{*}{$\begin{array}{l}\text { Bradycardia without cessation of } \\
\text { respiratory movements } \\
\text { Apnoea with } \\
\text { fall in } \mathrm{TcPo}_{2}>10 \mathrm{mmHg} \\
\text { Apnoea with fall in } \mathrm{TcPO}_{2} \\
\text { to below } 50 \mathrm{mmHg} \\
\text { Apnoea requiring additional } \\
\text { stimulation }\end{array}$} & 12 & 25 & 10 & 1 & 1 & 8 & $<0.02$ \\
\hline & 44 & 71 & $9 \dagger$ & $\mathbf{0}$ & 1 & 8 & $<0.01$ \\
\hline & 17 & 51 & $9+$ & 0 & 1 & 8 & $<0.005$ \\
\hline & 6 & 28 & 6 & 0 & 1 & 5 & $<0.05$ \\
\hline
\end{tabular}

*Wilcoxon's rank sum test for paired samples. $\mathrm{TTcPo}_{2}$ recordings unsatisfactory for 3 infants. 
from irregularly oscillating waterbeds appears to reduce apnoea, ${ }^{6}$ although regularly oscillating waterbeds may be less effective. ${ }^{7}$ Documented hazards of waterbeds include hypothermia, and the risk of accidental puncture. The rocking bed avoids these, and although there might have been problems with vomiting, no baby vomited during the study, nor has any done so in ordinary clinical use.

In this preliminary study, rocking appeared to diminish the frequency of apnoeic attacks, including those associated with hypoxia, and to reduce the need for active intervention to re-establish respiration. Bradycardia without cessation of movements on the impedance pneumogram (which may sometimes have been due to obstructive apnoea) was also less common. The rocking bed may prove helpful in the management of recurrent apnoea of prematurity.

\footnotetext{
References

1 Speidel B D, Dunn P M. Use of nasal continuous positive airway pressure to treat severe recurrent apnoea in very preterm infants. Lancet 1976; ii: 658-60.

2 Kuzemko J A, Paala J. Apnoeic attacks in the newborn treated with aminophylline. Arch Dis Child 1973; 48: 404-6.
}

3 Haas R H, Davies P A. Iatrogenic hazards in the newborn intensive care unit. In: Wharton B A, ed. Topics in perinatal medicine. Tunbridge Wells: Pitman Medical, 1980: 104-19.

4 Shapiro D L. Comments on the use of theophylline for apnea in premature infants. In: Lucey J F, Shannon D C, Soyka L F, eds. Apnea of prematurity. Report of the seventy-first Ross Conference on Pediatric Research. Columbus, Ohio: Ross Laboratories, 1977: 67-70.

5 Kattwinkel J, Nearman H S, Fanaroff A A, Katona P G, Klaus M H. Apnea of prematurity. Comparative therapeutic effects of cutaneous stimulation and nasal continuous positive airway pressure. $J$ Pediatr 1975; 86: 588-92.

- Korner A F, Guilleminault C, Van den Hoed J, Baldwin R B. Reduction of sleep apnea and bradycardia in preterm infants on oscillating waterbeds: a controlled polygraphic study. Pediatrics 1978 ; 61 : 528-33.

7 Jones R A K. A controlled trial of a regularly cycled oscillating waterbed and a non-oscillating waterbed in the prevention of apnoea in the preterm infant. Arch Dis Child 1981; 56: 889-91.

Correspondence to Dr S J Tuck, Jenny Lind Children's Department, Norfolk and Norwich Hospital, Brunswick Road, Norwich NR1 3SR.

Received 1 February 1982

\title{
Percutaneous alcohol absorption and skin necrosis in a preterm infant
}

\author{
V HARPIN AND N RUTTER \\ Department of Neonatal Medicine and Surgery, City Hospital, Hucknall Road, Nottingham
}

SUMMARY A 27-week gestation infant developed severe haemorrhagic skin necrosis on the back and buttocks after umbilical arterial catheterisation. Before catheterisation the skin was cleaned with methylated spirits. A blood alcohol level taken 18 hours after catheterisation showed a blood ethanol level of $259 \mathrm{mg} / 100 \mathrm{ml}$ and a blood methanol level of $26 \mathrm{mg} / 100 \mathrm{ml}$. We conclude that the methylated spirits caused this extensive skin damage and that percutaneous absorption via the readily permeable skin of this immature baby resulted in the dangerously high alcohol levels.

The keratinised stratum corneum which gives adult skin its barrier properties, begins to develop in the seventh month of fetal life. The thin poorly keratinised skin of a preterm baby is therefore an ineffective barrier and percutaneous absorption of toxic compounds-such as aniline dyes ${ }^{1}$ and hexachlorophane ${ }^{2}$-has been well documented. Damage to the skin itself has been reported in association with umbilical arterial catheterisation. It has been suggested that this might be due to vascular obstruction ${ }^{3}$ or to local toxic effects of cleansing solutions ${ }^{4}$ used to prepare the skin before catheterisation. We report a very immature baby who was shown to have dangerously high blood alcohol levels after skin cleansing with methylated spirits and who developed extensive skin damage of the type previously reported.

\section{Case report}

Twenty-seven week gestation twins were born to a healthy, 26-year-old mother who had had one previous normal pregnancy. The membranes had ruptured at 22 weeks' gestation.

Twin 1. The first, a boy weighing $865 \mathrm{~g}$, was born by difficult breech delivery. Pulsation of the cord ceased sometime before delivery. The baby was asphyxiated at birth and did not respond to resuscitation. He died aged 2 hours 20 minutes. 